\title{
Is there an association between economic performance and public satisfaction in health care?
}

\author{
Eddy M. M. Adang · George F. Borm
}

Received: 10 October 2006/Accepted: 12 February 2007/Published online: 14 March 2007

(C) Springer-Verlag 2007

\begin{abstract}
Earlier studies on the association between health systems' economic performance and public satisfaction were based on between-countries comparisons. This approach can be challenged as it ignores the fact that subjective measures like 'satisfaction' might be relative. Cohort analysis is a way of dealing with this issue as it focuses on within-countries comparisons. The association between change in satisfaction with health care systems and change in economic performance, determined by an output-orientated constant returns to scale DEA Malmquist model over the period 1995 to 2000/2002 using OECD data, is explored. The results show that a health care systems' economic performance is not associated with public satisfaction.
\end{abstract}

Keywords Public satisfaction - Data envelopment analysis - Malmquist index - Health system performance . Cohort analysis

\section{Introduction}

Most comparative studies that have investigated the association between economic performance of health care

\section{E. M. M. Adang ( $\square)$}

Department of Medical Technology Assessment/138, Radboud University Nijmegen Medical Centre, P.O. Box 9101, 6500 HB Nijmegen, The Netherlands e-mail: e.adang@mta.umcn.nl

\section{G. F. Borm}

Department of Epidemiology and Biostatistics, Radboud University Nijmegen Medical Centre, P.O. Box 9101, 6500 HB Nijmegen, The Netherlands systems and public satisfaction with health care systems were based on between-country comparisons [2, 3, 14, 25]. However, we challenge this approach and explore the relationship between satisfaction and economic performance using a different method.

Studies by Easterlin [10] show no relation between a country's gross domestic product (GDP) and the happiness levels of its citizens. Citizens of countries with a lower GDP were found to be equally happy compared to citizens of wealthier countries. In line with the findings of Easterlin, Oswald [19] concludes that, in a developed nation, economic progress buys only a small amount of extra happiness. Several European studies report no, or only a slightly positive, relationship between income and self-reported life satisfaction [28]. Absolute happiness levels cannot be explained by a nation's economic situation. Research shows that happiness is about, among other things, living up to the Joneses [26]. This implies that experiencing happiness is a relative concept [6]. Satisfaction too is a subjective measure [29]. An individual's satisfaction can be described as 'the extent of an individual's experience compared with his or her expectations' [1].

Research into the relationship between citizens' satisfaction with health care systems and economic health care system performance should not ignore this fact. A way of dealing with this, when researching this relationship, is to focus on changes within countries rather than differences between countries. In this case each country's population is its own reference and comparison with other countries is avoided. This adheres not only to economic findings but is also in accordance with epidemiological theory, which states that the use of cross-sectional methods requires that exposures should be objective and constant over time. If this is not the case, a longitudinal approach based on change over time should be used [24]. 
This paper presents a methodology that uses a withincountry approach to investigate the association between productivity of health care systems and satisfaction with health care systems. This will be investigated by researching the relationship between change in the health production function and change in satisfaction with the health care system in each European Union (EU 15) country over the periods 1995-2000 and 1995-2002.

\section{Methods}

The data

The data used in the health production function are from the OECD health database [18], an annual database developed by the OECD Health Policy Unit in Paris. Data about satisfaction with health care systems are from the Eurobarometer survey $[11,16]$. Both datasets, OECD and Eurobarometer, are based on the EU 15.

In the Eurobarometer health survey, European citizens in the 15 member states were asked a number of questions related to the running of health care systems in their countries. They were asked their opinion about the need for reforms and the level of health expenditures, and whether they were very satisfied, fairly satisfied, neither satisfied nor dissatisfied, or very dissatisfied with the health care system in their country. For the analysis of the change in satisfaction with the health care system between 1996 and 1999 , the percentages of the public that were "very satisfied and fairly satisfied" were used. For 2002 this information was not available and for the comparison between 1996 and 2002 the percentages of the public that stated that their health system performs well or that only minor changes are needed were used.

\section{The health production function}

The health production function used in this study is based on earlier research that compared health care systems using OECD Health Data [20, 21]. The authors of these latter studies referred to the health status model adopted by the Healthy People 2010 Project [4, 9, 31]. These models include the following determinants of health: (1) available medical care services and health expenditures; (2) the lifestyles, attitudes, and behaviours of the population; and (3) the social environment and population characteristics of a country. However, with only 15 countries it was necessary to limit the number of variables (input and output) in the health production function. The criteria for including variables in the health systems production function were adherence to the determinants of health as described by the Healthy People 2010 Project [4, $9,31]$, whether these variables were used in other empirical studies about health systems comparison, and if these variables were available for the EU 15 countries over at least the same period as the satisfaction with health systems data.

Keeping this in mind, the following input variables were selected: (1) The OECD country's share of GDP allocated to health care. This provides a measure of a country's health care expenditure [2, 3, 21, 32]. It was converted to a real health expenditure measure by dividing the original OECD data by the real volume of GDP in per capita terms (corrected for purchasing power parities); (2) The number of practicing physicians per 1,000 inhabitants, to represent access to health care (responsiveness) [13]. (3) Tobacco use as a lifestyle indicator, measured as the percentage of daily smokers among the adult population. Earlier research has shown that decreasing or abstaining from tobacco consumption increases life expectancy significantly [8, 27]. Other lifestyle variables, for example alcohol consumption, were found not to be statistically significant with respect to health output [8].

The outputs in the health production function were life expectancy at birth and infant mortality [21,32]. These two variables are less interrelated than other indicators of the population's health status such as mortality and life expectancy.

\section{Productivity measurement}

Productivity growth can be measured using methods that estimate the best practice frontier. These methods derive a country's productivity change from the changes in the inputs and/or outputs that move towards or away from the frontier on the one hand, and the shifts of the frontier on the other hand. Assume that for each country and time period, there exists a production possibility set, $S^{t}$, describing the transformation of input $x^{t}$ into output $y^{t}$. This means that, at any point in time, a country faces a best practice frontier, defining the maximum output the country can produce for a given amount of input. A country is not always located on the best practice frontier, but can be located anywhere in the production possibility set. Such a state is referred to as 'technically inefficient'.

Technical progress is continuously taking place in health care and is assumed to lead to productivity gains. There will be a time period $t+1$ where new technologies are implemented that were not present at time $t$. Technical progress over time leads to movement of the best practice frontier. This is illustrated graphically in Fig. 1. The change in productivity over time is measured by the Malmquist productivity index [5], which is usually pre- 


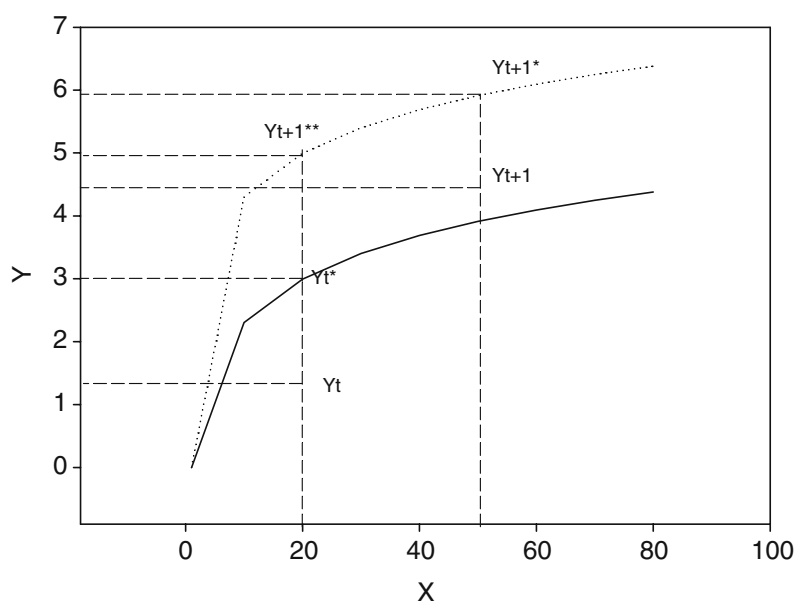

Fig. 1 Productivity change: efficiency and technology change. The figure shows a technology involving a single input vector $(X)$ and a single output vector $(Y)$. The solid and dotted lines indicate the technological frontier for the periods $t$ and $t+1$, respectively. The technological frontier shift is displayed by a country with input 20 and 50 in the first and second period produced at the levels $Y t$ and $Y t+1$, respectively. In each period the country was operating below the technological frontiers for that $\operatorname{period}\left(Y t^{*}\right.$ and $\left.Y t+1^{*}\right)$. Hence technical inefficiency is present in both periods. If the input remained at 20 , technical progress created the possibility to produce at level $Y t+1^{* *}$. The distance $Y t+1 *^{*}-Y t$ is the potential productivity change, consisting of technological change (frontier shift) and efficiency change (movement towards the frontier)

sented as a composite measure of efficiency change and technological change:

$$
\begin{aligned}
& m_{o}\left(y_{t}, x_{t}, y_{t+1}, x_{t+1}\right) \\
& \quad=\frac{d_{o}^{t+1}\left(y_{t+1}, x_{t+1}\right)}{d_{o}^{t}\left(y_{t}, x_{t}\right)}\left[\frac{d_{o}^{t}\left(y_{t+1}, x_{t+1}\right)}{d_{o}^{t+1}\left(y_{t+1}, x_{t+1}\right)} \times \frac{d_{o}^{t}\left(y_{t}, x_{t}\right)}{d_{o}^{t+1}\left(y_{t}, x_{t}\right)}\right]^{0.5},
\end{aligned}
$$

where the part outside square brackets measures the change in the output-orientated measure of technical efficiency between periods $t$ and $t+1$. The part between brackets is a measure of technological change. A value of $\frac{d_{o}^{t+1}\left(y_{t+1}, x_{t+1}\right)}{d_{o}^{t}\left(y_{t} x_{t}\right)}$ greater than one will indicate positive efficiency change from period $t$ to period $t+1$ while a value less than one indicates an efficiency decline. The same applies to technological change (i.e., frontier shift).

The Malmquist productivity index can be computed using either linear programming techniques such as data envelopment analysis (DEA) or econometric techniques. Since the work of Färe et al. [12], it has become popular to calculate empirical Malmquist productivity indices using linear programming techniques. According to Coelli [7], in the non-profit service sector, where random influences are less of an issue, multiple-output production is important, prices are difficult to define and behavioural assumptions such as cost minimization or profit maximization are difficult to justify, the DEA approach may often be the optimal choice.
Measuring change

Subtracting the values for 1996 from the 1999 and 2002, satisfaction scores respectively, determined the change in satisfaction with health care systems (see Tables 1,2). Changes in productivity, efficiency and technology were determined by an output-orientated constant returns to scale DEA Malmquist model over the periods 1995-2000 and 1995-2002, respectively.

\section{Undesirable outcomes}

In DEA models it is assumed that outputs should be increased or inputs decreased to improve performance or to reach the best practice frontier. However, our health production function uses, among other variables, infant mortality as output and practicing physicians as input. These variables point in the wrong direction: infant mortality should decrease rather than increase and the number of practicing physicians should increase instead of decrease. We followed Zhu [34] and applied a linear decreasing transformation (of the general form: $Y=a-b X$ ). Zhu [34] argues that a linear transformation is a good choice for a DEA model, because it preserves the convexity.

Association between productivity change and change in satisfaction

To investigate the association between productivity change and change in satisfaction with health care systems,

Table 1 Public satisfaction with the health care systems in EU 15 countries between 1996 and 1999 (adapted from Eurobarometer 1996 and 1999 [11] and from Mossialos [10, 14])

\begin{tabular}{lllc}
\hline Country & $\begin{array}{l}\text { Very and fairly } \\
\text { satisfied (\%) } \\
1996\end{array}$ & $\begin{array}{l}\text { Very and fairly } \\
\text { satisfied }(\%)\end{array}$ & $\begin{array}{c}\text { Satisfaction } \\
\text { change }(\%) \\
1996-1999\end{array}$ \\
\hline Austria & 63.3 & 83.4 & 20.1 \\
Belgium & 70.1 & 77 & 6.9 \\
Denmark & 90 & 75.8 & -14.2 \\
Finland & 86.4 & 74.3 & -12.1 \\
France & 65.1 & 78.2 & 13.1 \\
Germany & 66 & 49.9 & -16.1 \\
Greece & 18.4 & 18.6 & 0.2 \\
Ireland & 49.9 & 47.7 & -2.2 \\
Italy & 16.3 & 46.3 & 30 \\
Luxembourg & 71.1 & 71.6 & 0.5 \\
The Netherlands & 72.8 & 73.2 & 0.4 \\
Portugal & 19.9 & 25.1 & 5.2 \\
Spain & 35.6 & 47.6 & 12 \\
Sweden & 67.3 & 58.7 & -8.6 \\
United Kingdom & 48.1 & 55.7 & 7.6 \\
\hline
\end{tabular}


Table 2 Citizens' opinions about health care reforms in the EU 15 countries between 1996 and 2002 (adapted from Eurobarometer, 1996 and 2002 and 1997[11];Mossialos [10, 14])

\begin{tabular}{llll}
\hline Country & $\begin{array}{l}\text { Runs well or } \\
\text { minor changes } \\
\text { needed }(\%) \\
1996\end{array}$ & $\begin{array}{l}\text { Runs well or } \\
\text { minor changes } \\
\text { needed }(\%)\end{array}$ & $\begin{array}{l}\text { Change in } \\
\text { Citizen's } \\
\text { attitudes to health } \\
\text { reforms }(\%) \\
1996-2002\end{array}$ \\
\hline Austria & 73.7 & 67.2 & -6.5 \\
Belgium & 75.7 & 65.1 & -10.6 \\
Denmark & 91.6 & 51.6 & -40 \\
Finland & 90.5 & 72.6 & -17.9 \\
France & 66.5 & 63.9 & -2.6 \\
Germany & 75.4 & 47.1 & -28.3 \\
Greece & 29.3 & 18.8 & -10.5 \\
Ireland & 50.1 & 20.4 & -29.7 \\
Italy & 18.5 & 30.9 & 12.4 \\
Luxembourg & 75.8 & 67.7 & -8.1 \\
The Netherlands & 77 & 45.6 & -31.4 \\
Portugal & 23 & 14.3 & -8.7 \\
Spain & 44.5 & 45.6 & 1.1 \\
Sweden & 72.6 & 47.7 & -24.9 \\
United Kingdom & 42 & 31.2 & -10.8 \\
\hline & & & \\
\hline
\end{tabular}

Spearman correlation coefficients were calculated. A bootstrap approach was used to obtain 95\% confidence intervals.

\section{Results}

In Ireland, Sweden, Finland, Denmark and Germany, peoples' satisfaction with their health care system decreased from 1996 to 1999, whereas in the other ten EU 15 countries satisfaction grew (Table 1). Over the period 1996-2002 more citizens felt that fundamental changes were needed or that a complete rebuild of the system was necessary (Table 2). The correlation between these two measures was high $(0.83, P<0.01)$. Tables 3 and 4 display the results of the output orientated constant returns to scale DEA Malmquist models. The total factor productivity has increased in all EU 15 countries over both periods, i.e. 1995-2000 and 1995-2002, implying better economic performance. This is almost solely due to technological progress (frontier shift) (Tables 3, 4).

The results show no correlation between satisfaction and economic performance: the Spearman correlation coefficient between the change in public satisfaction with the health system and the Malmquist economic performance index (1995-2000) was $0.02(95 \%$ CI $-0.5,0.5)$ and the correlation coefficient for the change in citizens attitudes to major health care reforms with change in
Table 3 Economic performance of EU 15 countries 1995-2000. Values $>1$ show an increase over 1995-2000, values $<1$ show a decline

\begin{tabular}{llll}
\hline Country & $\begin{array}{l}\text { Malmquist } \\
\text { index }\end{array}$ & $\begin{array}{l}\text { Efficiency } \\
\text { change }\end{array}$ & $\begin{array}{l}\text { Frontier } \\
\text { shift }\end{array}$ \\
\hline Austria & 1.02602 & 1.00000 & 1.02602 \\
Belgium & 1.02168 & 1.00673 & 1.01485 \\
Denmark & 1.02100 & 1.00209 & 1.01887 \\
Finland & 1.09444 & 0.97266 & 1.12521 \\
France & 1.02500 & 1.01096 & 1.01388 \\
Germany & 1.02093 & 0.99958 & 1.02136 \\
Greece & 1.00771 & 0.98382 & 1.02428 \\
Ireland & 1.03219 & 0.99256 & 1.03993 \\
Italy & 1.02848 & 1.01873 & 1.00957 \\
Luxembourg & 1.22050 & 0.99671 & 1.22453 \\
The Netherlands & 1.01625 & 1.00000 & 1.01625 \\
Portugal & 1.05768 & 1.00615 & 1.05121 \\
Spain & 1.02939 & 0.99066 & 1.03910 \\
Sweden & 1.18375 & 1.00412 & 1.17889 \\
United Kingdom & 1.02052 & 1.00549 & 1.01495 \\
Average & 1.05370 & 0.99935 & 1.05459 \\
\hline
\end{tabular}

Table 4 Economic performance of EU 15 countries 1995-2002. Values $>1$ show an increase over 1995-2002, values $<1$ show a decline

\begin{tabular}{llll}
\hline Country & $\begin{array}{l}\text { Malmquist } \\
\text { index }\end{array}$ & $\begin{array}{l}\text { Efficiency } \\
\text { change }\end{array}$ & $\begin{array}{l}\text { Frontier } \\
\text { shift }\end{array}$ \\
\hline Austria & 1.05234 & 1.00000 & 1.05234 \\
Belgium & 1.03064 & 1.01410 & 1.01631 \\
Denmark & 1.02518 & 1.00344 & 1.02166 \\
Finland & 1.14686 & 1.00000 & 1.14686 \\
France & 1.03345 & 1.01249 & 1.02070 \\
Germany & 1.03116 & 1.00405 & 1.02700 \\
Greece & 1.01240 & 0.98430 & 1.02855 \\
Ireland & 1.02759 & 0.99805 & 1.02960 \\
Italy & 1.02920 & 1.01512 & 1.01388 \\
Luxembourg & 1.10686 & 1.00567 & 1.10062 \\
The Netherlands & 1.02017 & 1.00000 & 1.02017 \\
Portugal & 1.07405 & 1.00629 & 1.06734 \\
Spain & 1.02258 & 0.98894 & 1.03402 \\
Sweden & 1.22811 & 1.00044 & 1.22757 \\
United Kingdom & 1.02189 & 1.00057 & 1.02130 \\
Average & 1.05750 & 1.00223 & 1.05519 \\
\hline
\end{tabular}

economic performance (1995-2002) was 0.00 (95\% CI $0.46,0.47)$.

No significant bi-variate correlation was found between change in satisfaction with health systems and the following parameters: change in life expectancy, change in infant mortality and change in health expenditures as per- 
centage of GDP (see Table 5). Further, a significant correlation was noted between change in total health expenditures as percentage of GDP and change in infant mortality $(P=0.005)$.

\section{Discussion}

We explored the association between the economic performance of health care and public satisfaction with health care systems by means of 'within country comparisons'. By doing so we took into account that satisfaction is a relative concept that systematically differs between countries.

The results show no association between a health care system's economic performance and change in satisfaction with the health care system. This implies that improving economic performance of health systems may not necessarily improve citizens' satisfaction with those health systems.

These findings are to a certain extent supported by Blendon [2], who compared World Health Organization (WHO) efficiency rankings for 17 industrialised countries (EU15 plus the United States and Canada) with perceptions of their citizens and found, using a between-countries approach, a non-significant negative relation between public satisfaction with health care systems and economic performance of health care systems (Spearman's rho -0.235).

According to Sitzia and Wood [30], the provision of health care, measures of accessibility, availability and convenience are consistently associated with higher satisfaction. All these variables represent determinants of 'economic' performance and as such might be included in a production function together with other economic variables. The nature of the relation of these variables, together in a production function, and satisfaction with the health systems is, however, not explored. Blendon et al. [3] suggest that, among the countries surveyed, public satisfaction was associated with levels of health care spending per capita. Regarding the public's attitude to health spending, the public offers support for increasing health expenditure but it opposes raising taxes or health insurance contributions. Mossialos [16] also concluded that satisfaction might be related to higher spending on health care. These results were explored in a between-countries comparison construct.

According to Simon [29], when, on an individual level, health system performance falls short of the level of aspiration, the level of aspiration begins to adjust itself downward until goals reach levels that are practically attainable. At a certain point in time people might well be unsatisfied with their health system. At a later point in time, under circumstances in which health system performance might be constant or has even decreased over time, it is very well possible that satisfaction with the health care system has increased compared to the earlier time point as aspiration levels have adjusted downward. This conceptual reasoning could very well explain our findings.

Our production function assumes that a better health care system that strives to perform best optimises the relationship between life expectancy, infant mortality, and physician density, total health expenditure and tobacco use. However, these domains may not be visible to average citizens and consequently do not enter their utility function directly. Thus, it might be that the general public is unaware of technological progress and efficiency gain, because

Table 5 Bi-variate correlations of change. GDP Gross domestic product

\begin{tabular}{|c|c|c|c|c|c|c|}
\hline Test & Variables & & $\begin{array}{l}\text { Difference in } \\
\text { satisfaction }\end{array}$ & $\begin{array}{l}\text { Difference in } \\
\text { life expectancy }\end{array}$ & $\begin{array}{l}\text { Difference in } \\
\text { infant mortality }\end{array}$ & $\begin{array}{l}\text { Difference total health } \\
\text { expenditures as } \\
\text { percentage of GDP }\end{array}$ \\
\hline \multirow[t]{12}{*}{ Spearman's rho } & \multirow{3}{*}{$\begin{array}{l}\text { Difference in } \\
\text { satisfaction }\end{array}$} & Correlation coefficient & 1.000 & 0.128 & 0.376 & 0.050 \\
\hline & & Significance (2-tailed) & - & 0.650 & 0.168 & 0.860 \\
\hline & & $\mathrm{N}$ & 15 & 15 & 15 & 15 \\
\hline & \multirow{3}{*}{$\begin{array}{l}\text { Difference in life } \\
\text { expectancy }\end{array}$} & Correlation coefficient & 0.128 & 1.000 & -0.034 & 0.217 \\
\hline & & Significance (2-tailed) & 0.650 & - & 0.904 & 0.436 \\
\hline & & $\mathrm{N}$ & 15 & 15 & 15 & 15 \\
\hline & \multirow{3}{*}{$\begin{array}{l}\text { Difference in infant } \\
\text { mortality }\end{array}$} & Correlation coefficient & 0.376 & -0.034 & 1.000 & $0.685^{*}$ \\
\hline & & Significance (2-tailed) & 0.168 & 0.904 & - & 0.005 \\
\hline & & $\mathrm{N}$ & 15 & 15 & 15 & 15 \\
\hline & \multirow{3}{*}{$\begin{array}{l}\text { Difference total health } \\
\text { expenditures as } \\
\text { percentage GDP }\end{array}$} & Correlation coefficient & 0.050 & 0.217 & $0.685^{*}$ & 1.000 \\
\hline & & Significance (2-tailed) & 0.860 & 0.436 & 0.005 & - \\
\hline & & $\mathrm{N}$ & 15 & 15 & 15 & 15 \\
\hline
\end{tabular}

* Correlation is significant at the 0.01 level (2-tailed) 
the health care system is not transparent for most individuals in as far as they do not experience it themselves. Consequently, these individuals focus mainly on the private expenses they experience due to tax increases and higher contributions for their health-insurance policies.

Laine et al. [15] showed that there might be a trade-off between efficiency and quality of care. They found that certain quality of care indicators were negatively associated with efficiency. On the other hand they also found that other quality indicators were positively associated with efficiency. It might be that, on average, these developments compensate each other and result in overall low correlation coefficients. This can be seen in a study by Kerssens et al. [14], who found a mean correlation between quality of GP care and WHO overall performance of 0.11 , ranging from 0.85 (my GP has a good understanding of my problems) to -0.31 (my GP makes sure that I can see a specialist within 2 weeks of being referred).

Our study has some limitations. The small sample size $(n=15)$ might limit the robustness of the results. The choice of variables in the production function of this study is debatable. Much of the critique of the World Health Report [32] had to do with completeness of the production function and the choice of the inputs [17, 22, 23]. However, it should be noted that the variables in our production function are well-accepted inputs and outputs for production functions on a health system level and are often used in empirical studies on health system performance. Despite the general acceptance of the output variables in our production function, it may be that, for example, "life expectancy at birth" could be better measured in terms of healthy life expectancy. However, healthy life expectancy as a variable might be valid in a cross-sectional comparison approach but limited in a longitudinal approach as The World Health Report 2003 [33], describes: "Healthy life expectancies for 2002 are not comparable with those published for 2001 due to the incorporation of new epidemiological information". Although the variables in our health production function are well chosen, as argued above, it should be acknowledged that this function is far from complete due to methodological restrictions. The discussion surrounding the WHO report [32] showed that there is rarely a consensus about the choice of outputs to be measured. This choice is essentially a political choice. Our research did not focus on the political choice, nor was it intended to do so. For that particular kind of research, alternative approaches such as conjoint analysis and multilevel models may be more useful to policymakers.

It should be noted that this study does not intend to benchmark individual country's health systems but presents a within-countries approach and an exploration of the association between health system performance and satisfaction with that health system.
Public satisfaction with the health care system is important. Policymakers aim to satisfy both the public and the need for productivity gain in health care. However, one should remain aware that focussing on economic performance does not necessarily lead to people becoming more satisfied with their health care system.

\section{References}

1. Asadi-Lari, M., Tamburini, M., Gray, D.: Patients' needs, satisfaction, and health related quality of life: towards a comprehensive model. Health Qual. Life Outcomes 2, 32 (2004)

2. Blendon, R.J., Kim, M., Benson, J.M.: The public versus the world health organization on health system performance. Health Aff. 20(3), 10-11 (2001)

3. Blendon, R.J., Leitman, R., Morrison, I., et al.: Satisfaction with health systems in ten nations. Health Aff. 9,185-192 (1990)

4. Blum, H.L.: Planning for Health. Human Sciences Press, New York (1981)

5. Caves, D.W., Christensen, L.R., Diewert, W.E.: The economic theory of index numbers and the measurement of input, output and productivity. Econometrica 50, 1393-1414 (1982)

6. Clark, A.E., Oswald, A.J.: Unhappiness and unemployment. Econ. J. 104, 648-659 (1994)

7. Coelli, T.: An Introduction to Efficiency and Productivity Analysis. Kluwer, Boston (1997)

8. Contoyannis, P., Jones, A.W.: Socio-economic status, health and lifestyle. J. Helath Econ. 23, 965-995 (2004)

9. Department of Health and human Services. Healthy People 2010. Public Health Service, US Department of Health and Human Services, Washington DC (2000)

10. Easterlin, R.: Does economic growth improve the human lot? Some empirical evidence. In: Davis, P.A., Reder, M.W. (eds.) Nations and Households in Economic Growth: Essays in honor of Moses Abramovitz (2003), pp. 89-125. Academic, New York (1974)

11. Eurobarometer 52.1, 1999 and 1963. Available at www.ec.europa.eu/research/quality-of-life/eurobarometer.html

12. Färe, R., Grosskopf, S., Lindgren, B., et al.: Productivity Development in Swedish Hospitals: A Malmquist Output Index Approach. Discussion Paper No 89-3. Southern Illinois University (1989)

13. Grubaugh, S.G., Santerre, R.E.: Comparing the performance of health care systems: an alternative approach. South. Econ. J. 60(4), 1030-42 (1994)

14. Kerssens, J.J., Groenewegen, P.P., Sixma, H.J. et al.: Comparison of patient evaluations of health care quality in relation to WHO measures of achievement in 12 European countries. Bull. World Health Organ. 2(82), 106-114 (2004)

15. Laine, J., Finne-Soveri, U.H., Björkgren, M.: The association between quality of care and technical efficiency in long term care. Int. J. Qual. Health Care 17(3), 259-267 (2005)

16. Mossialos, E.: Citizens' views on health care systems in the 15 member states of the European union. Health Econ. 6, 109-116 (1997)

17. Navarro, V.: Can health care systems be compared using a single measure of performance? Am. J. Public Health 92, 31-33 (2002)

18. OECD: OECD HEALTH DATA 2005, Electronic datafile release October 2005. Paris 2005

19. Oswald, A.J.: Happiness and economic performance. Econ. J. 107, 1815-1831 (1997)

20. Reinhardt, U.E., Hussey, P.S., Anderson, G.F.: Cross-national comparisons of health systems using OECD data, 1999. Health Aff. 21(3), 169-81 (2002) 
21. Retzlaff-Roberts, D., Chang, C.F., Rubin, R.M.: Technical efficiency in the use of health care resources: a comparison of OECD countries. Health Policy 69, 55-72 (2004)

22. Richardson, J., Wildman, J., Robertson, I.K.: A critique of the World Health Organization's evaluation of health system performance. Health Econ. 12, 355-366 (2003)

23. Robbins, A.: WHO ranking of health systems. Science 294(5548), 1832-1833 (2001)

24. Rothman, K.J.: Modern Epidemiology, Little and Brown, Boston/ Toronto, pp. 70-72 (1986)

25. Schoen, C., Blendon, R.J., DesRoches, C.M., Osborn, R.: Comparison of health care system views and experiences in five nations, 2001. New York Commonwealth Fund (2001)

26. Scitovsky, T.: The Joyless Economy. Oxford University Press, New York (1976)

27. Shaw, J.W., Horrace, W.C., Vogel, R.J.: The determinants of life expectancy: an analysis of the OECD Health Data. South. Econ. J. 71(4), 768-783 (2005)
28. Shields, M.A., Wheatley Price, S.: Exploring the economic and social determinants of psychological well-being and perceived social support in england. J. R. Stat. Soc. A 168(3), 513-537 (2005)

29. Simon, H.A.: Theories of decision making in economics and behavioral science. Am. Econ. Rev. 49(3), 253-283 (1959)

30. Sitzia, J., Wood, N.: Patient satisfaction: A review of issues and concepts. Social Sci. Med. 45(12), 1829-1843 (1997)

31. Starfield, B.: Health services research: a working model. N. Engl. J. Med. 289(2), 132-136 (1973)

32. WHO: World health report 2000 Geneva, World Health Organization (2000)

33. WHO: World health report 2003 Geneva, World Health Organization (2003)

34. Zhu, J.: Quantitative Models for Performance Evaluation and Benchmarking. Springer, Boston (2003) 